\title{
Venom based neural modulators (Review)
}

\author{
JIAO CHEN, XIAO-MING LIU and YUAN ZHANG \\ Department of Pediatric Internal Medicine, Xuzhou Children's Hospital, Xuzhou, Jiangsu 221002, P.R. China
}

Received May 15, 2017; Accepted September 12, 2017

DOI: $10.3892 /$ etm.2017.5483

\begin{abstract}
Different types of neuronal nicotinic acetylcholine receptors (nAChRs) are expected to occur in vivo, most structure-activity relationship studies have been carried out for just a few neuronal subtypes. The present review enlightens current aspects of venom modulators of nAChRs. Important electronic databases such as PubMed or Google scholar were explored for the collection of latest studies in the field. Clinical and basic research has shown that cholinergic receptors play a role in several disorders of the nervous system such as chronic pain, Alzheimer's disease and addiction to nicotine, alcohol and drugs. Unfortunately, the lack of selective modulators for each subtype of nAChR makes their pharmacological characterization difficult, which has slowed the development of therapeutic nAChR modulators with high selectivity and absence of off-target side-effects. Animal venoms have proven to be an excellent natural source of bioactive molecules with activity against ion channels. The present review concludes that the presence of small-molecule nAChR modulators in spider venoms support the use of venoms as a potential source of novel modulators.
\end{abstract}

\section{Contents}

1. Introduction

2. Role of nAChRs in human disease

3. Modulators of nAChRs as drugs and insecticides

4. Venom-derived modulators of nAChRs

5. nAChR modulators from other venomous animals

6. Rationale for examining spider venoms as a source of novel nAChR modulators

7. Conclusions

Correspondence to: Dr Xiao-Ming Liu, Department of Pediatric Internal Medicine, Xuzhou Children's Hospital, 18 Sudibei Road, Xuzhou, Jiangsu 221002, P.R. China

E-mail: minglx@yeah.net

Key words: venom, nicotinic acetylcholine receptors

\section{Introduction}

Recent studies indicate that imbalance of the cholinergic system in human brain via nicotinic acetylcholine receptors (nAChRs) are linked to various neurological disorders $(1,2)$ while mutations in the $\mathrm{nAChR}$ can lead to frontal lobe epilepsy. These findings have prompted research into the development of drugs that target neuronal cholinergic receptors. Nevertheless, most of the chemical components under trial lack selectivity, or hardly improve the medical condition $(3,4)$. The discovery of new therapeutic agents is currently a challenge because of the complex arrangement of subunits of neuronal cholinergic receptors expressed in human brain (5) and the fact that their roles under physiological and pathological conditions are not fully understood (6).

To facilitate studies of the pharmacology of $\mathrm{nAChRs}$, a search for new nAChR modulators in spider and scorpion venoms was carried out using a high-throughput FLIPR assay to rapidly identify 'hit' venoms (7). The probability of finding native cholinergic modulators was expected to be high because arachnid venoms are estimated to contain approximately 1 million different components, and even though less than $0.01 \%$ of these molecules have been studied (8), many of them are peptidic toxins that act on diverse types of ionic channels (9).

\section{Role of nAChRs in human disease}

The role of $\mathrm{ACh}$ is as important as their molecular target, nAChRs (10). It is synthesised by the enzyme choline acetyltransferase that transfers an acetyl group from acetyl-CoA to choline. Its precursor, choline, is endogenously produced, although it is also absorbed in the small intestine to reach the levels required to accomplish several functions (11). For example, choline is a precursor for the biosynthesis of constituents of plasma membrane such as phosphatidylcholine and sphingomyelin (11). Furthermore, choline is a methyl group donor; and methylation is needed to regulate of expression of genes and mediate biosynthetic reactions. A deficiency in choline has been related to liver damage and impairment of cognitive functions in older people (12). Indeed, choline supplementation enhances cognitive functions in patients with schizophrenia (13). De-regulation of cholinergic function is linked to the function and expression of nAChRs. For instance, chronic administration of nicotine can induce an increase in the number of neurons containing $\alpha 4 \beta 2 \mathrm{nAChRs}$ in the glutamatergic subthalamic nucleus, a cerebral area related to 
movement control (14), or downregulate the function of other subtype nAChRs. Below we discuss different pre-clinical and clinical evidence of the consequences of smoking, and links between de-regulation of nAChRs and major symptoms in neurodegenerative diseases.

Post-mortem studies in the brain of people who suffer from Alzheimer's and Parkinson's disease, epilepsy and schizophrenia showed that the density of $\alpha 4 \beta 2 \mathrm{nAChRs}$ is extremely low (15). The degeneration of cholinergic circuits was confirmed in human brains after the development of nicotine radioligands for imaging studies in vivo. For example, in vivo studies of brains of people suffering from Alzheimer's disease showed a decrease of $\alpha 4 \beta 2$ nAChRs and the density of nAChRs in arteries appeared to be affected as well (16). In patients suffering from Alzheimer's and Parkinson's disease, there is a notable loss of cholinergic projections into the cerebral cortex, and this has been considered as part of the reason for the impaired cognition observed in these patients, although the loss of the cortical cholinergic activity in people with Parkinson's disease is notable (17). In addition, depressive symptoms in patients with Parkinson's disease is strongly correlated to loss of $\alpha 4 \beta 2 \mathrm{nAChRs}$ in the neuronal frontal corticomesostriatal circuitry, while those patients with mild cognitive impairment were associated with low levels of $\alpha 4 \beta 2$ in the neuronal frontal corticobasal ganglia-limbic-cerebellar circuitry that includes some areas of the former circuitry. Furthermore, $\alpha 4 \beta 2 *$ nAChRs are widely distributed in the brain and are not restricted to cholinergic or dopaminergic neurons. Thus, downregulation of this heteromeric subtype may lead to dysfunction of other neuronal circuitries (18). Cholinergic deregulation in the hippocampus may be associated with cognitive problems because this cerebral region is related to functions of learning and memory (19) and this correlation between dysfunction of neuronal circuitry and cognitive functions is observed in various neuronal disorders.

$\mathrm{nAChRs}$ have also been identified in immune cells, and upregulation of its activity in these cells has been linked to cardiovascular diseases such as atherosclerosis in smokers (20). Recent evidence suggests that the mechanism underlying this process could be activation of $\alpha 7 \mathrm{nAChRs}$ that trigger transcription of cell-adhesion proteins on endothelial cells (21). These proteins, such as E-selectin, favour the attachment of monocytes, and it might lead to abnormal formation of fibrous plaques in vascular smooth muscle cells. Notably, the duration and amount of nicotine administered via smoking are dependent variables, and when these reach critical values it may facilitate the activation of numerous $\mathrm{nAChR}$ subtypes that are linked to signalling cascades and cause abnormal proliferation of neuronal and non-neuronal cells (22).

\section{Modulators of nAChRs as drugs and insecticides}

Several clinical trials are being carried out to evaluate potential drugs that target nAChRs. For instance, some nicotine analogues are been used to facilitate quitting smoking (23). Varenicline (trade name Chantix ${ }^{\circledR}$ ) is currently being used for treatment of nicotine addiction and is a partial agonist of the $\alpha 4 \beta 2$ and $\alpha 3^{*}$ receptors. However, varenicline also activates the $\alpha 7 \mathrm{nAChR}$ (24), and it has been suggested that its mechanism of action involves is by modulation of several nAChRs (25) that contributes to decreasing the levels of dopamine that were previously increased by nicotine in the limbic system. This in turn prevents reward response induced by smoking (26). Imaging studies in vivo of smokers under treatment with varenicline showed that $\alpha 4 \beta 2 *$ nAChRs are saturated after administration of the drug at low or high doses, and withdrawal effects were not detected. Unfortunately, varenicline can also cause adverse effects in smokers under treatment; nausea is very common and is one of the primary reasons for withdrawal for treatment (27). The side-effect is likely to be mediated by activation of ganglionic nAChRs. This is likely to be a common problem when using therapeutic agents that target multiple subtypes of nAChRs distributed across the peripheral nervous system.

As previously mentioned, $\mathrm{nAChRs}$ are also important insecticide targets, and the so-called neonicotinoid insecticides that target insect $\mathrm{nAChRs}$ are one of the most successful classes of chemical insecticides. Nicotinoid insecticides are derived from nicotine, the major alkaloid derived from leaves and stems of the tobacco plant Nicotiana tabacum; nicotine is a secondary metabolite that is used by the plant to defend against herbivorous insects (28). The neonicotinoids are chemically similar to nicotine but they have low toxicity to mammals as they were engineered to bind selectively to insect nAChRs (29). However, like the majority of chemical insecticides, most neonicotinoids are broadly active against a wide range of insect pests, including beneficial insects such bees (30). Honeybees are efficient pollinators that mediate plant reproduction, and therefore it would be highly desired to engineer insecticides that preferentially target $\mathrm{nAChRs}$ in insect pests but not beneficial insects such as pollinators or predators of the targeted pest. Matsuda et al (31) compared the complex formed between imidacloprid, the most successful neonicotinoid, and $\alpha 2 \beta 1 \mathrm{nAChRs}$ from the honeybee Apis mellifera and the green peach aphid Myzus persicae. They found a remarkable structural difference between the binding sites for imidacloprid in the two nAChRs, with a hidden and broader binding groove in the aphid $\mathrm{nAChR}$ compared with the bee receptor. The authors suggested that linking imidacloprid to a molecular fragment that fits the groove of the aphid $\mathrm{nAChR}$ could improve the selectivity for insect pests over bees. To summarise, neonicotinoids are generally safe for humans but they could be toxic for small vertebrates such as birds and beneficial insects such as honeybees.

The selectivity of some toxins for nAChRs has facilitated the development of fluorescent binding probes and radioligands for use in biological sciences and nuclear medicine (32). It has helped to determine the distribution of nAChRs in the brain of rodents and humans including in people suffering from Alzheimer's and Parkinson's disease. For example, $\alpha$-bungarotoxin a 74-residue peptide isolated from venom of Bungarus multicinctus, was used to affinity purify the nAChR from the electric organ of T. marmorata. $\alpha$-Bungarotoxin has also been useful for visualizing the distribution of nAChRs in the brain and in the electric organ from Torpedo californica, and for identifying clones expressing epitopes from nAChR in Escherichia coli (33). Recently, it was shown that Alexa Fluor 555-labelled $\alpha$-bungarotoxin labels GABAA-Rs expressed in HEK-293 cells (32), and this binding is inhibited 
by bicuculline, a competitive antagonist at GABAA-Rs, and $d$-tubocurarine, a non-selective nAChRs antagonist and a competitive antagonist at GABAA-Rs. This finding is not surprising because type-A GABAergic receptors are members of the pentameric Cys-loop ligand-gated ion channel family, like nAChRs (34). The selectivity of $\alpha$-bungarotoxin has been used to discover new functional subunits of nAChRs, such as the $\alpha 7$ subunit of $n A C h R s$. This is a receptor similar to the heteropentameric $\mathrm{nAChR}$ reported previously because $\alpha$-bungarotoxin blocked its activation and was able to bind the subunit $\alpha 7$. Furthermore, iodinated $\alpha$-bungarotoxin has been used in competition studies to evaluate the specificity of radioligands towards $\alpha 7 \mathrm{nAChRs.}$

Nicotine radioligands are being used for imaging studies using positron emission tomography (PET) (35). Note that radioligands are typically used for imaging studies at subtherapeutic doses and consequent safety rarely poses an issue. The first nicotine-based radioligand developed to label $\mathrm{nAChR}$ was $\left[{ }^{11} \mathrm{C}\right]$-nicotine. Other radioligands that are chemically-related to nicotine are still under development with some promising results, such as $\left[{ }^{18} \mathrm{~F}\right]-\mathrm{ZW}-104$ and $\left[{ }^{18} \mathrm{~F}\right]-\mathrm{AZAN}-\alpha$. The first probe is a selective ligand for the $\beta 2$ subunit of $n A C h R$ and has been tested pre-clinically. $\left[{ }^{18} \mathrm{~F}\right]-\mathrm{AZAN}-\alpha$ has been assayed in human studies with promising results (35). It reached the brain in $<20$ min after injection, and selectively bound the $\alpha 4 \beta 2$ subtype (36). In this study the specificity for $\alpha 4 \beta 2$ was evaluated through administration of varenicline, a selective partial agonist of $\alpha 4 \beta 2$ that is used to aid smoking cessation (37). The specificity of the radiotracer for the receptor was confirmed after the drug blocked totally the uptake of $\left[{ }^{18} \mathrm{~F}\right]-\mathrm{AZAN}-\alpha$. A-85380 is another example of a radiotracer (38) that has high affinity for $\alpha 4 \beta 2 \mathrm{nAChRs}$. It allowed mapping of the distribution of nAChRs in the brain of smokers and non-smokers. Furthermore, it has been used to confirm that expression of $\alpha 4 \beta 2$ in the brain of patients with Alzheimer's disease and dementia is significantly decreased, and is correlated with the degree of cognitive impairment (39).

The development of agents to be used for human brain imaging in vivo has been extended to design tracers selective for the $\alpha 7$ subtype. Some promising results has been obtained even where the homomeric $\alpha 7$ in the human brain is found in low concentrations compared to $\alpha 4 \beta 2$. For example, $\left[{ }^{18} \mathrm{~F}\right]-$ NS-10743 and $\left[{ }^{18} \mathrm{~F}\right]-A$ SEM showed high affinity toward $\alpha 7$ and the distribution of these radioligands were found in brain areas where $\alpha 7$ is densely expressed, such as frontal cortex and hippocampus. To prove the specificity of the agents, the specific ligand SSR180771, which is a selective and partial agonist at human and rodent subtype $\alpha 7$, was used in competition studies. The tracers showed their specificity for $\alpha 7$ when these were displaced by SSR180771. As discussed above, part of the problem with nAChR modulators as drug leads, insecticides and pharmacological tools is their lack of selectivity. This has made it difficult to dissect the role of nAChRs in different physiological processes as well as their role in pathophysiological processes such as cognitive dysfunction, depression, chronic anxiety, analgesia, inflammation and neurodegenerative diseases (40). Thus, there is still a great need to develop novel nAChR modulators that are both potent and selective. As discussed below, animal venoms have provided some of the most potent and selective $\mathrm{nAChR}$ modulators described to date and represent a potential source of new nAChR modulators.

\section{Venom-derived modulators of nAChRs}

Venoms from marine cone snails (genus Conus) have been extensively studied, although scarcely $0.1 \%$ of the predicted total number of venom compounds have been characterized so far (41). Conus venoms are replete with disulfide-bridged peptides, named conopeptides or conotoxins that target a wide range of voltage and ligand-gated ion channels, including nAChRs. Indeed, the venoms of marine cone snails are the largest natural source of potent and selective $\mathrm{nAChR}$ blockers (reviewed in ref. 42). There are at least seven families of $\alpha$-conotoxins that bind specific muscle and neuronal nAChR subtypes with high selectivity (43). $\alpha$-Conotoxins are the smallest conopeptides (generally 12-20 amino acid residues) that competitively binds to the ACh binding site of nAChRs. Their general framework is denoted CC-Xm-C-Xn-C, where $\mathrm{C}$ represents a cysteine residue and $\mathrm{X}$ corresponds to the two inter-cysteine loops that contain a variable region of amino acid residues. The number of amino acid residues is indicated as $\mathrm{m} / \mathrm{n}$ and $\alpha$-conotoxins with a $3 / 5$ loop size combination are usually purified from the venom of Conus species that feed on fish and are typically active on mammalian neuromuscular nAChRs, while other conopeptides with 4/3, 4/4, 4/5, 4/6 and 4/7 loop combinations preferentially act on mammalian neuronal nAChRs $(41,42)$.

Several studies of the interaction between $\alpha$-conotoxins and AChBP have contributed to our understanding of how $\alpha$-conotoxins can be selective for a particular nAChR (44). Basically, the different electrostatic interactions and hydrogen bonds between aromatic residues of $\alpha$-conotoxins and amino acid residues outside of the ACh binding pocket are found in the conotoxins that block nAChRs while those conotoxins with fewer interactions are more likely to be agonists (45). These studies have also helped develop a structural model of the pharmacophore of $\alpha$-conotoxins. It is delimitated by the two loops between the cysteine residues. One is conserved and determines the binding to the $\mathrm{nAChR}$ and the second loop consists of a variable sequence that determines their selectivity for a particular subunit of the $\mathrm{nAChR}(41,42)$.

\section{5. nAChR modulators from other venomous animals}

Snake venom is another large source of proteins and peptides that target nAChRs (46). The most abundant proteins described so far in elapid, colubrid and psammophid snakes are the three-finger toxins (3FTx) that contain between 60 to 74 amino acid residues with molecular masses ranging between 6000 and $8000 \mathrm{Da}$ (47). Most 3FTxs target nAChRs. These toxins are divided into three types differentiated by the number of cysteines and the inter-cysteine spacing. Type I and type III $\alpha$-neurotoxins with eight cysteine residues target neuromuscular nAChRs. Type II $\alpha$-neurotoxins contain an extra pair of cysteine residues which form an additional disulfide bond that stabilises loop 2 (48). This additional disulfide bond facilitates interaction with neuronal $\alpha 7$ and $\alpha 9-10$ nAChRs, while maintaining affinity for the neuromuscular $\alpha 1 \mathrm{nAChR}$. Another interesting group of 3FTxs are the so-called 'non-conventional 
toxins' that have an additional disulfide bond that is not in the central loop II but instead in the N-terminal loop I (49). Examples of non-conventional toxins that block nAChRs are candoxin from Bungarus candidus and the weak toxin (WTX) from Naja Kaouthia.

\section{Rationale for examining spider venoms as a source of novel $n A C h R$ modulators}

Spiders are well known to produce venoms that contain diverse chemical structures such as peptides up to $10 \mathrm{kDa}$, proteins, amino acids and acylpolyamines (50). This complex and heterogeneous mixture of compounds allows spiders to prey on, and defend themselves against a wide range of prey and predators. The different repertoire of acylpolyamines appears to have evolved to allow predation of different species of invertebrates and small vertebrates.

Acylpolyamines could selectively block ionotropic glutamate receptors from insects and vertebrates including mammals (51). Because glutamate is the main neurotransmitter at the neuromuscular junctions in insects, block of glutamatergic receptors by acylpolyamines induces paralysis. However, acylpolyamine toxins are also reported to antagonise nAChRs. The basic backbone of acylpolyamines is an aromatic acyl group and the polyamine chain that form the essential part of the molecule. These two features are generally present in acylpolyamines derived from funnel-web, trap door and tarantula spiders (52). The length of the polyamine chain and the degree of hydrophobicity determines the affinity for nAChRs. Recently, a toxin denoted VdTX-1 was purified from the venom of the Brazilian theraphosid spider Vitalius dubius (53). This component has a molecular weight of $728 \mathrm{Da}$ and it non-competitively blocks nAChRs. Surprisingly, this toxin was photosensitive, which might be why this toxin, and perhaps related toxins in other spider venoms, was not identified in previous studies.

\section{Conclusions}

There is clearly some evidence for the presence of smallmolecule $\mathrm{nAChR}$ modulators in spider venoms, suggesting that these venoms could be explored more systematically as a potential source of novel modulators.

\section{References}

1. Mitra S, Mucha M, Khatri SN, Glenon R, Schulte MK and Bult-Ito A: Attenuation of compulsive-like behavior through positive allosteric modulation of $\alpha 4 \beta 2$ nicotinic acetylcholine receptors in non-induced compulsive-like mice. Front Behav Neurosci 10: 244, 2017.

2. Tregellas JR, Tanabe J, Rojas DC, Shatti S, Olincy A, Johnson L, Martin LF, Soti F, Kem WR, Leonard S, et al: Effects of an o 7-nicotinic agonist on default network activity in schizophrenia. Biol Psychiatry 69: 7-11, 2011.

3. de Moura FB and McMahon LR: The contribution of $\alpha 4 \beta 2$ and non- $\alpha 4 \beta 2$ nicotinic acetylcholine receptors to the discriminative stimulus effects of nicotine and varenicline in mice. Psychopharmacology (Berl) 234: 781-792, 2017.

4. Pammolli F, Magazzini L and Riccaboni M: The productivity crisis in pharmaceutical R\&D. Nat Rev Drug Discov 10: 428-438, 2011.

5. Gotti C, Moretti M, Gaimarri A, Zanardi A, Clementi F and Zoli M: Heterogeneity and complexity of native brain nicotinic receptors. Biochem Pharmacol 74: 1102-1111, 2007.
6. Tuesta LM, Fowler CD and Kenny PJ: Recent advances in understanding nicotinic receptor signaling mechanisms that regulate drug self-administration behavior. Biochem Pharmacol 82: 984-995, 2011

7. Tsetlin VI: Three-finger snake neurotoxins and Ly6 proteins targeting nicotinic acetylcholine receptors: Pharmacological tools and endogenous modulators. Trends Pharmacol Sci 36: 109-123, 2015.

8. King GF and Coaker $\mathrm{H}$ : The future of venoms-based drug discovery: An interview with Glenn King. Future Med Chem 6: 1613-1615, 2014.

9. Xie S, Feng J, Yu C, Li Z, Wu Y, Cao Z, Li W, He X, Xiang M and Han S: Identification of a new specific Kv1.3 channel blocker, Ctri9577, from the scorpion Chaerilus tricostatus. Peptides 36: 94-99, 2012.

10. Jurado-Coronel JC, Avila-Rodriguez M, Capani F, Gonzalez J, Moran VE and Barreto GE: Targeting the nicotinic acetylcholine receptors (nAChRs) in astrocytes as a potential therapeutic target in Parkinson's disease. Curr Pharm Des 22: 1305-1311, 2016.

11. Zeisel SH and da Costa KA: Choline: An essential nutrient for public health. Nutr Rev 67: 615-623, 2009.

12. Fioravanti $M$ and Yanagi $M$ : Cytidinediphosphocholine (CDP-choline) for cognitive and behavioural disturbances associated with chronic cerebral disorders in the elderly. Cochrane Database Syst Rev 2: CD000269, 2005.

13. Knott V, de la Salle S, Choueiry J, Impey D, Smith D, Smith M, Beaudry E, Saghir S, Ilivitsky V and Labelle A: Neurocognitive effects of acute choline supplementation in low, medium and high performer. Pharmacol Biochem Behav 131: 119-129, 2015.

14. Xiao C, Miwa JM, Henderson BJ, Wang Y, Deshpande P, McKinney SL and Lester HA: Nicotinic receptor subtype-selective circuit patterns in the subthalamic nucleus. J Neurosci 35: 3734-3746, 2015.

15. Shen $\mathrm{J}$ and $\mathrm{Wu} \mathrm{J}$ : Nicotinic cholinergic mechanisms in Alzheimer's disease. Int Rev Neurobiol 124: 275-292, 2015.

16. Bauwens M, Mottaghy FM and Bucerius J: PET imaging of the human nicotinic cholinergic pathway in atherosclerosis. Curr Cardiol Rep 17: 67, 2015.

17. Müller MLTM and Bohnen NI: Cholinergic dysfunction in Parkinson's disease. Curr Neurol Neurosci Rep 13: 377, 2013.

18. Emre M: Dementia associated with Parkinson's disease. Lancet Neurol 2: 229-237, 2003.

19. Kutlu MG and Gould TJ: Nicotinic receptors, memory, and hippocampus. Curr Top Behav Neurosci 23: 137-163, 2015.

20. Wada T, Naito M, Kenmochi H, Tsuneki H and Sasaoka T: Chronic nicotine exposure enhances insulin-induced mitogenic signaling via up-regulation of alpha7 nicotinic receptors in isolated rat aortic smooth muscle cells. Endocrinology 148: 790-799, 2007.

21. Alamanda V, Singh S, Lawrence NJ and Chellappan SP: Nicotine-mediated induction of E-selectin in aortic endothelial cells requires Src kinase and E2F1 transcriptional activity. Biochem Biophys Res Commun 418: 56-61, 2012.

22. Koga M, Kanaoka Y, Ohkido Y, Kubo N, Ohishi K, Sugiyama K, Yamauchi A and Kataoka Y: Varenicline aggravates plaque formation through $\alpha 7$ nicotinic acetylcholine receptors in ApoE KO mice. Biochem Biophys Res Commun 455: 194-197, 2014.

23. Rollema H, Coe JW, Chambers LK, Hurst RS, Stahl SM and Williams KE: Rationale, pharmacology and clinical efficacy of partial agonists of alpha4beta $2 \mathrm{nACh}$ receptors for smoking cessation. Trends Pharmacol Sci 28: 316-325, 2007.

24. Mihalak KB, Carroll FI and Luetje CW: Varenicline is a partial agonist at alpha4beta2 and a full agonist at alpha7 neuronal nicotinic receptors. Mol Pharmacol 70: 801-805, 2006.

25. Lotfipour S, Mandelkern M, Alvarez-Estrada M and Brody AL: A single administration of low-dose varenicline saturates $\alpha 4 \beta 2 *$ nicotinic acetylcholine receptors in the human brain. Neuropsychopharmacology 37: 1738-1748, 2012.

26. Rollema H, Coe JW, Chambers LK, Hurst RS, Stahl SM and Williams KE: Rationale, pharmacology and clinical efficacy of partial agonists of alpha4beta2 nACh receptors for smoking cessation. Trends Pharmacol Sci 28: 316-325, 2007.

27. Lam S and Patel PN: Varenicline: A selective alpha4beta2 nicotinic acetylcholine receptor partial agonist approved for smoking cessation. Cardiol Rev 15: 154-161, 2007.

28. Isman MB: Botanical insecticides, deterrents, and repellents in modern agriculture and an increasingly regulated world. Annu Rev Entomol 51: 45-66, 2006. 
29. Brown LA, Ihara M, Buckingham SD, Matsuda $\mathrm{K}$ and Sattelle DB: Neonicotinoid insecticides display partial and super agonist actions on native insect nicotinic acetylcholine receptors. J Neurochem 99: 608-615, 2006.

30. Faucon JP, Aurières C, Drajnudel P, Mathieu L, Ribière M, Martel AC,Zeggane S, Chauzat MP and Aubert MF: Experimental study on the toxicity of imidacloprid given in syrup to honey bee (Apis mellifera) colonies. Pest Manag Sci 61: 111-125, 2005.

31. Matsuda K, Kanaoka S, Akamatsu M and Sattelle DB: Diverse actions and target-site selectivity of neonicotinoids: Structural insights. Mol Pharmacol 76: 1-10, 2009.

32. Hannan S, Mortensen M and Smart TG: Snake neurotoxin $\alpha$-bungarotoxin is an antagonist at native $\operatorname{GABA}(\mathrm{A})$ receptors. Neuropharmacology 93: 28-40, 2015.

33. Gershoni JM: Expression of the $\alpha$-bungarotoxin binding site of the nicotinic acetylcholine receptor by Escherichia coli transformants. Proc Natl Acad Sci USA 84: 4318-4321, 1987.

34. Corringer PJ, Poitevin F, Prevost MS, Sauguet L, Delarue M and Changeux JP: Structure and pharmacology of pentameric receptor channels: From bacteria to brain. Structure 20: 941-956, 2012.

35. Bauwens M, Mottaghy FM and Bucerius J: PET imaging of the human nicotinic cholinergic pathway in atherosclerosis. Curr Cardiol Rep 17: 67, 2015.

36. Wong DF, Kuwabara H, Kim J, Brasic JR, Chamroonrat W, Gao Y, Valentine H, Willis W, Mathur A, McCaul ME, et al: PET imaging of high-affinity $\alpha 4 \beta 2$ nicotinic acetylcholine receptors in humans with ${ }^{18} \mathrm{~F}$-AZAN, a radioligand with optimal brain kinetics. J Nucl Med 54: 1308-1314, 2013.

37. Rollema H, Coe JW, Chambers LK, Hurst RS, Stahl SM and Williams KE: Rationale, pharmacology and clinical efficacy of partial agonists of alpha4beta $2 \mathrm{nACh}$ receptors for smoking cessation. Trends Pharmacol Sci 28: 316-325, 2007.

38. Kimes AS, Horti AG, London ED, Chefer SI, Contoreggi C, Ernst M, Friello P, Koren AO, Kurian V, Matochik JA, et al: 2- $\left.{ }^{18} \mathrm{~F}\right] \mathrm{F}-\mathrm{A}-85380$ : PET imaging of brain nicotinic acetylcholine receptors and whole body distribution in humans. FASEB J 17: 1331-1333, 2003

39. Colloby SJ, Perry EK, Pakrasi S, Pimlott SL, Wyper DJ, McKeith IG, Williams ED and O'Brien JT: Nicotinic ${ }^{123} \mathrm{I}-$ 5IA-85380 single photon emission computed tomography as a predictor of cognitive progression in Alzheimer's disease and dementia with Lewy bodies. Am J Geriatr Psychiatry 18: 86-90, 2010.

40. García AP, Aitta-aho T, Schaaf L, Heeley N, Heuschmid L, Bai Y, Barrantes FJ and Apergis-Schoute J: Nicotinic $\alpha 4$ receptor-mediated cholinergic influences on food intake and activity patterns in hypothalamic circuits. PLoS One 10: e0133327, 2015.

41. Lebbe EKM, Peigneur S, Wijesekara I and Tytgat J: Conotoxins targeting nicotinic acetylcholine receptors: An overview. Mar Drugs 12: 2970-3004, 2014.
42. Lewis RJ, Dutertre S, Vetter I and Christie MJ: Conus venom peptide pharmacology. Pharmacol Rev 64: 259-298, 2012.

43. Wang S, Zhao C, Liu Z, Wang X, Liu N, Du W and Dai Q: Structural and functional characterization of a novel $\alpha$-conotoxin Mrl.7 from Conus marmoreus targeting neuronal nAChR $\alpha 3 \beta 2$, $\alpha 9 \alpha 10$ and $\alpha 6 / \alpha 3 \beta 2 \beta 3$ subtypes. Mar Drugs 13: 3259-3275, 2015.

44. Dutertre S, Ulens C, Büttner R, Fish A, van Elk R, Kendel Y, Hopping G, Alewood PF, Schroeder C, Nicke A, et al: AChBPtargeted $\alpha$-conotoxin correlates distinct binding orientations with nAChR subtype selectivity. EMBO J 26: 3858-3867, 2007.

45. Dutertre S, Nicke A, Tyndall JD and Lewis RJ: Determination of $\alpha$-conotoxin binding modes on neuronal nicotinic acetylcholine receptors. J Mol Recognit 17: 339-347, 2004.

46. Utkin YN: Animal venom studies: Current benefits and future developments. World J Biol Chem 6: 28-33, 2015.

47. Roly ZY, Islam MM and Reza MA: A comparative in silico characterization of functional and physicochemical properties of 3FTx (three finger toxin) proteins from four venomous snakes. Bioinformation 10: 281-287, 2014.

48. Sunagar K, Jackson TNW, Undheim EAB, Ali SA, Antunes A and Fry BG: Three-fingered RAVERs: Rapid accumulation of variations in exposed residues of snake venom toxins. Toxins (Basel) 5: 2172-2208, 2013.

49. Tsetlin VI: Three-finger snake neurotoxins and Ly6 proteins targeting nicotinic acetylcholine receptors: Pharmacological tools and endogenous modulators. Trends Pharmacol Sci 36: 109-123, 2015.

50. Estrada G, Villegas E and Corzo G: Spider venoms: A rich source of acylpolyamines and peptides as new leads for CNS drugs. Nat Prod Rep 24: 145-161, 2007.

51. Olsen CA, Kristensen AS and Strømgaard K: Small molecules from spiders used as chemical probes. Angew Chem Int Ed Engl 50: 11296-11311, 2011.

52. Strømgaard K, Jensen LS and Vogensen SB: Polyamine toxins: Development of selective ligands for ionotropic receptors. Toxicon 45: 249-254, 2005.

53. Rocha-E-Silva TA, Rostelato-Ferreira S, Leite GB, da Silva PI Jr, Hyslop S and Rodrigues-Simioni L: VdTX-1, a reversible nicotinic receptor antagonist isolated from venom of the spider Vitalius dubius (Theraphosidae). Toxicon 70: 135-141, 2013.

This work is licensed under a Creative Commons Attribution-NonCommercial-NoDerivatives 4.0 International (CC BY-NC-ND 4.0) License. 